\title{
Teaching and curiosity: sequential drivers of cumulative cultural evolution in the hominin lineage
}

\author{
van Schaik, Carel P ; Pradhan, Gauri R ; Tennie, Claudio
}

\begin{abstract}
Many animals, and in particular great apes, show evidence of culture, in the sense of having multiple innovations in multiple domains whose frequencies are influenced by social learning. But only humans show strong evidence of complex, cumulative culture, which is the product of copying and the resulting effect of cumulative cultural evolution. The reasons for this increase in complexity have recently become the subject of extensive debate. Here, we examine these reasons, relying on both comparative and paleoarcheological data. The currently best-supported inference is that culture began to be truly cumulative (and so, outside the primate range) around 500,000 years ago. We suggest that the best explanation for its onset is the emergence of verbal teaching, which not only requires language and thus probably coevolved with the latter's evolution but also reflects the overall increase in proactive cooperation due to extensive allomaternal care. A subsequent steep increase in cumulative culture, roughly $75 \mathrm{ka}$, may reflect the rise of active novelty seeking (curiosity), which led to a dramatic range expansion and steep increase in the diversity and complexity of material culture. A final, and continuing, period of acceleration began with the Neolithic (agricultural) revolution.
\end{abstract}

DOI: https://doi.org/10.1007/s00265-018-2610-7

Posted at the Zurich Open Repository and Archive, University of Zurich

ZORA URL: https://doi.org/10.5167/uzh-183670

Journal Article

Accepted Version

Originally published at:

van Schaik, Carel P; Pradhan, Gauri R; Tennie, Claudio (2019). Teaching and curiosity: sequential drivers of cumulative cultural evolution in the hominin lineage. Behavioral Ecology and Sociobiology, 73:2.

DOI: https://doi.org/10.1007/s00265-018-2610-7 


\section{Behavioral Ecology and Sociobiology \\ Teaching and Curiosity: sequential drivers of cumulative cultural evolution in the hominin lineage \\ --Manuscript Draft--}

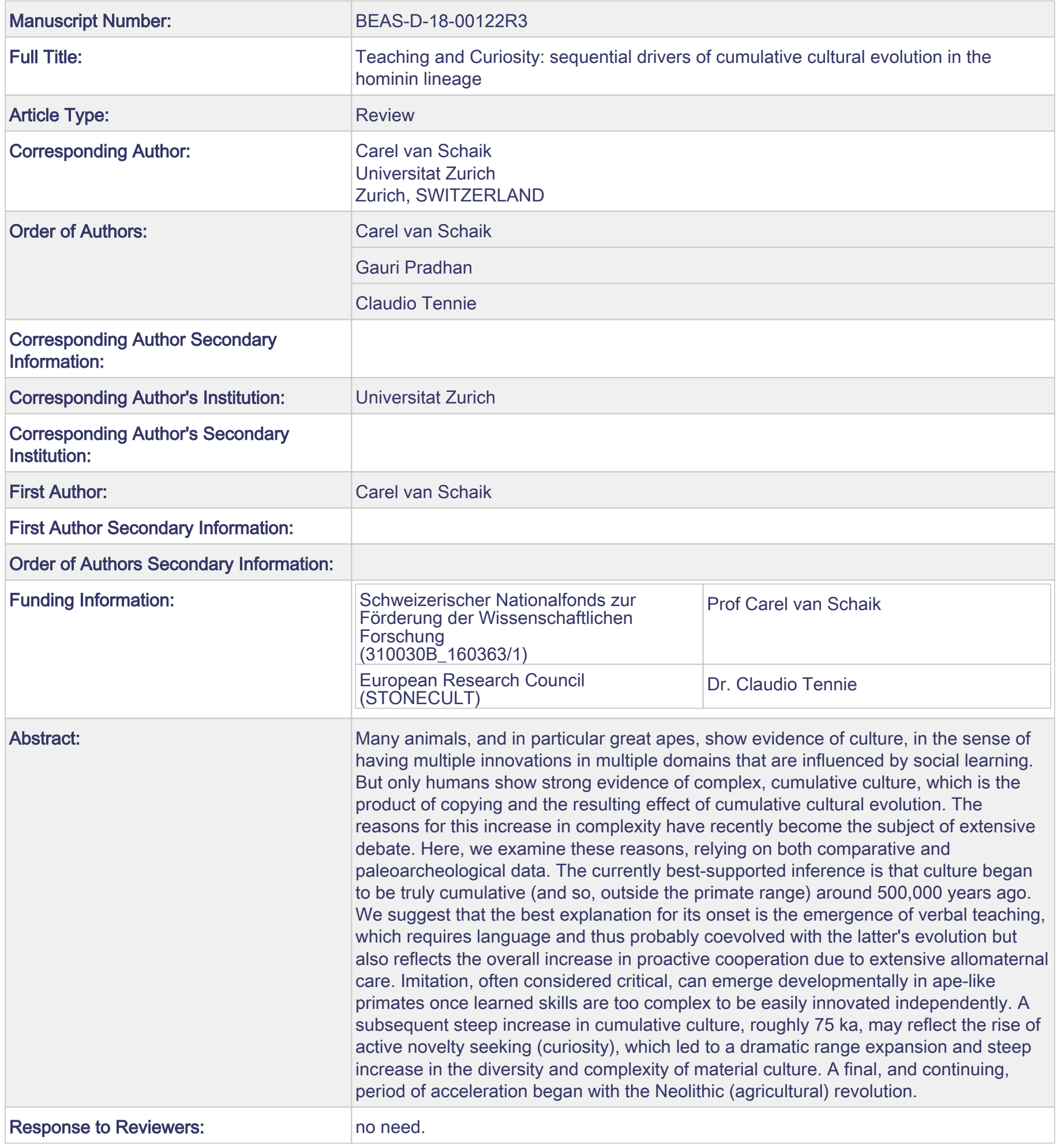




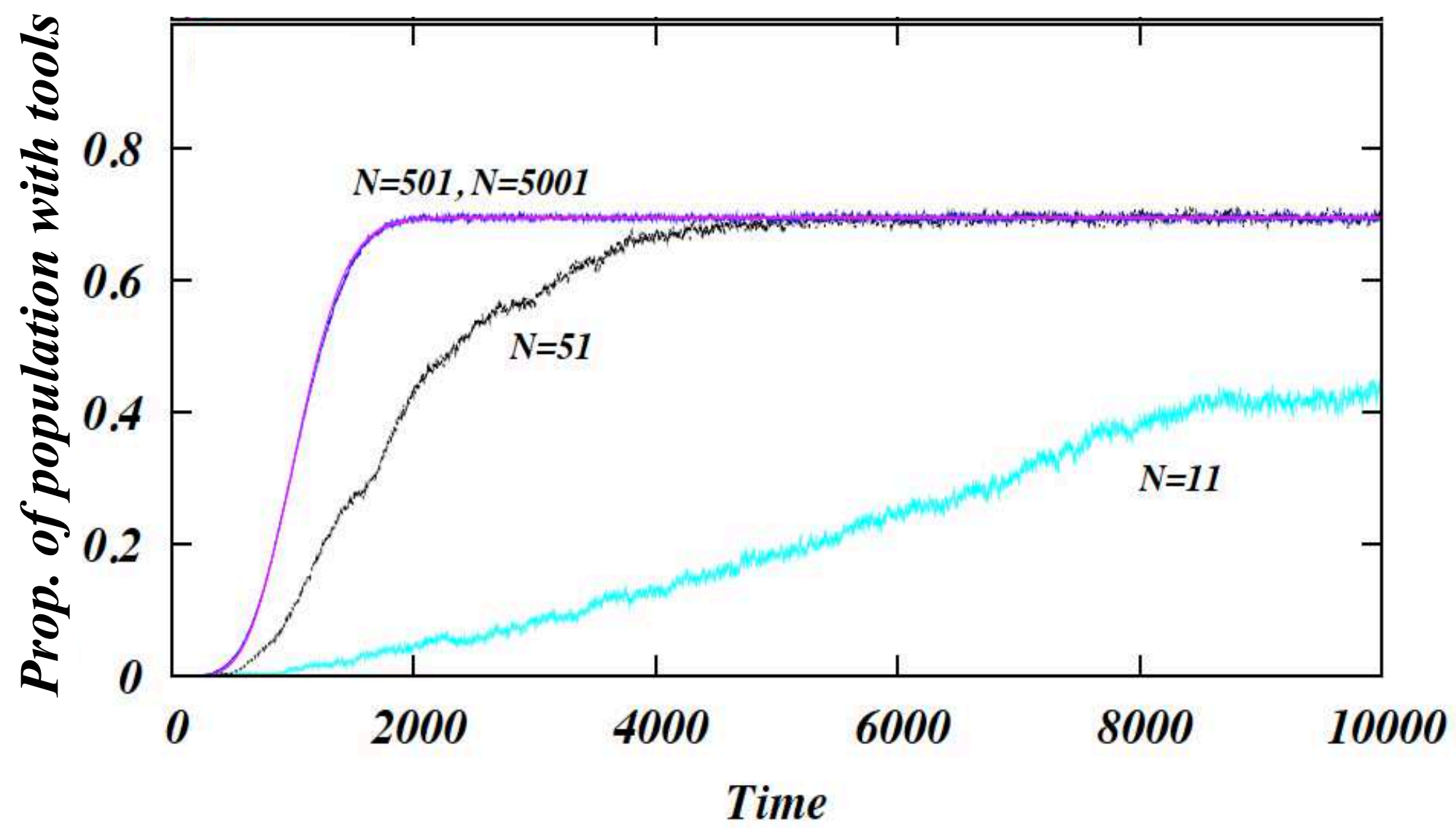




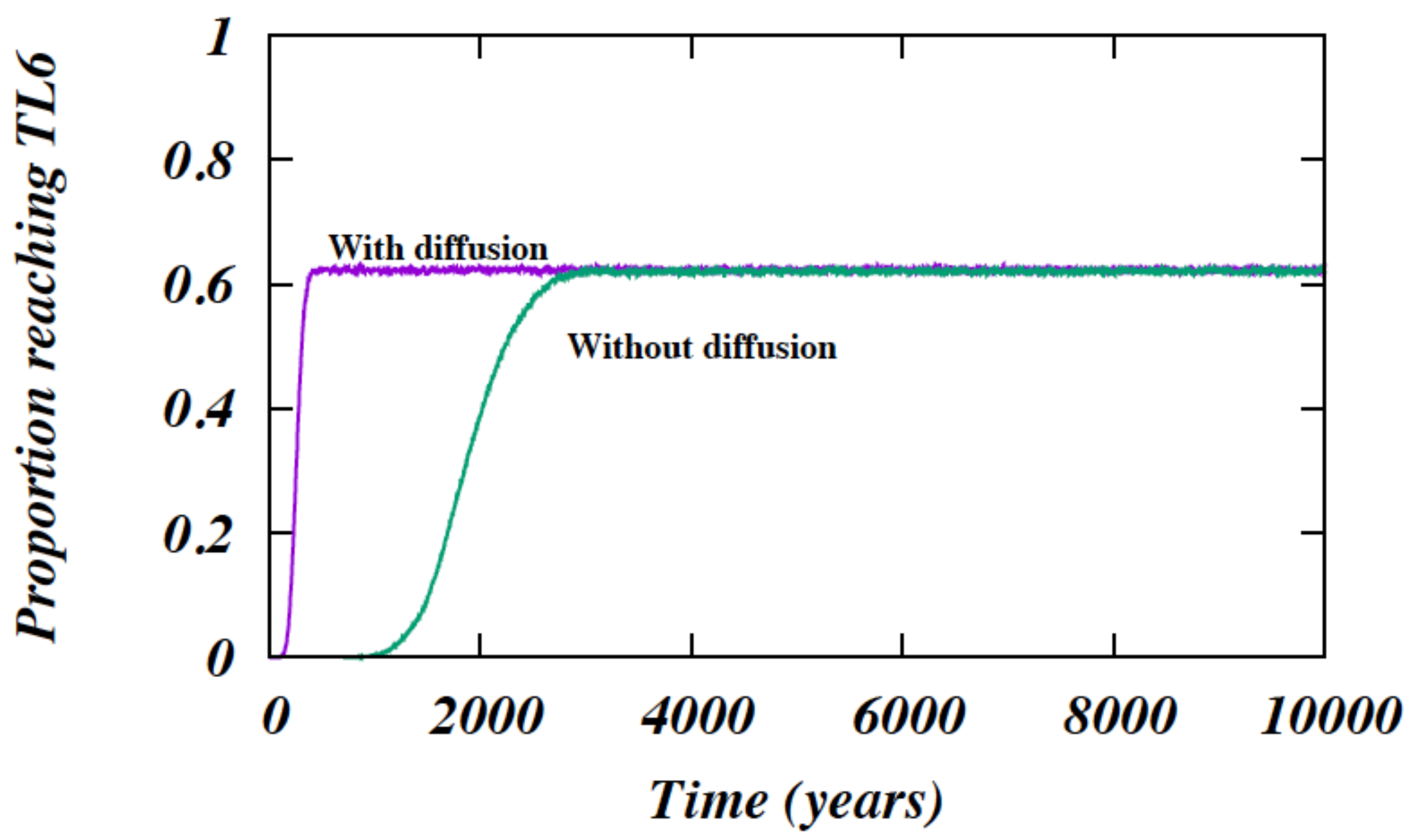




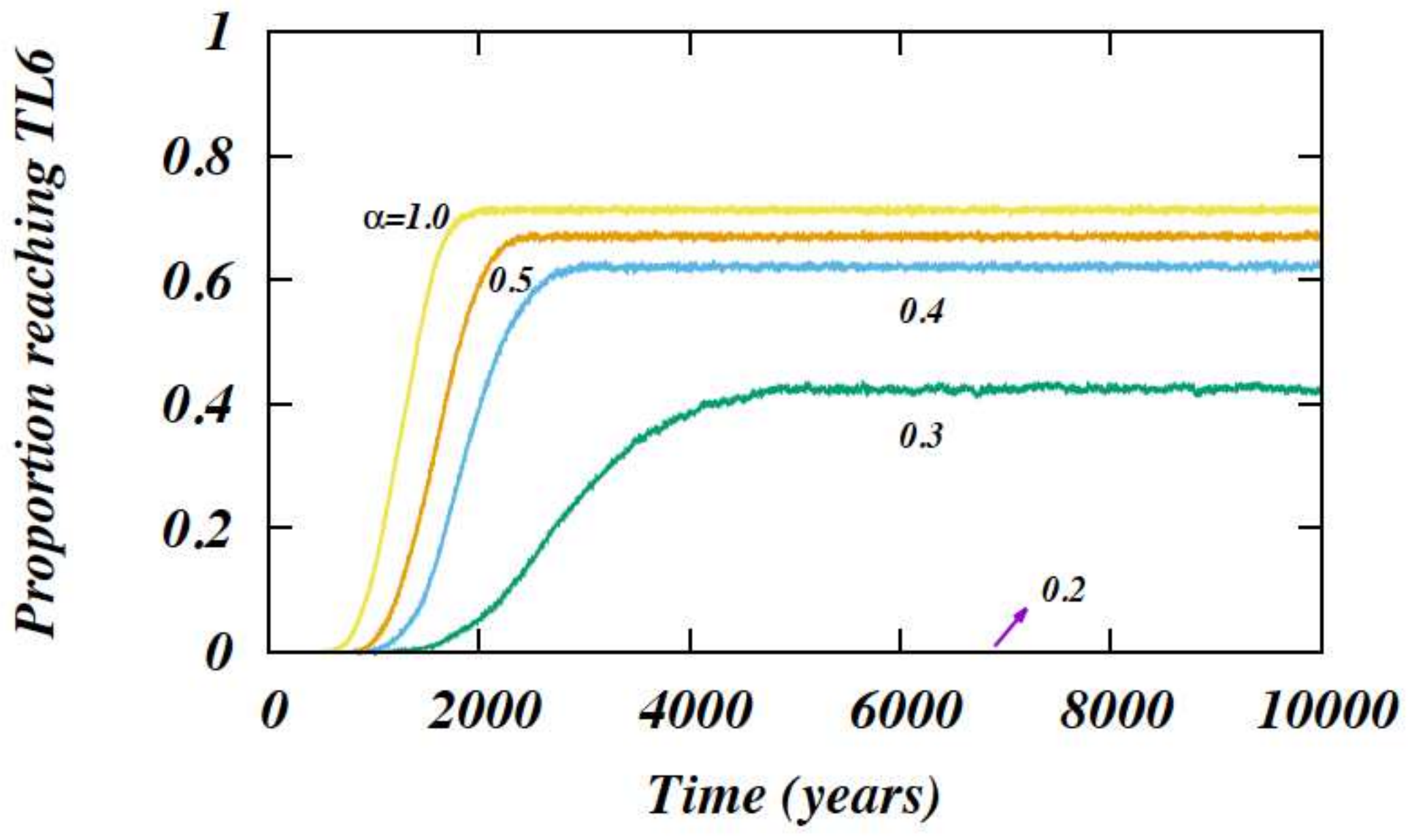


Table 1

The major leaps in the pace of cultural evolution during human evolution

\begin{tabular}{|l|l|l|}
\hline $\begin{array}{l}\text { Major } \\
\text { transition }\end{array}$ & When? & Major driver \\
\hline $\begin{array}{l}\text { Homo } \\
\text { heidelbergensis }\end{array}$ & $\begin{array}{l}\text { after } \\
500 \mathrm{ka}\end{array}$ & $\begin{array}{l}\text { Intensive cooperation: involving } \\
\text { use of language and teaching of } \\
\text { young, both driven by extensive } \\
\text { allomaternal care and systematic } \\
\text { food sharing. }\end{array}$ \\
\hline Out-of-Africa & ca $75 \mathrm{ka}$ & $\begin{array}{l}\text { Curiosity unleashed: sudden } \\
\text { failure of regular foraging, leading } \\
\text { to need to invent new resource } \\
\text { exploitation methods, leading to } \\
\text { novel niche dimensions. }\end{array}$ \\
\hline Neolithic & ca $10 \mathrm{ka}$ & $\begin{array}{l}\text { Incentives for specialization: after } \\
\text { development of sedentism and then } \\
\text { agriculture, producing increased } \\
\text { incentives to innovate, due to } \\
\text { private benefits from specialization } \\
\text { and trade, and need for effective } \\
\text { wars. }\end{array}$ \\
\hline
\end{tabular}


$\begin{array}{ll}1 & \text { This article is a contribution to the Topical Collection Social complexity: } \\ 2 & \text { patterns, processes, and evolution - Guest Editors: Peter Kappeler, Susanne } \\ 3 & \text { Shultz, Tim Clutton-Brock, and Dieter Lukas }\end{array}$

4
5
6
7

8 Teaching and Curiosity: sequential drivers of cumulative cultural

9 evolution in the hominin lineage

10

11

12 Carel P. van Schaik ${ }^{1^{*}}$

13 Gauri R. Pradhan²

14 Claudio Tennie ${ }^{3}$

15

16

17 *: corresponding author: vschaik@aim.uzh.ch

18 1: Department of Anthropology, University of Zurich, 8057 Zurich,

19 Switzerland

20 2: Department of Physics, University of South Florida, Tampa, FL 33620-

21 7100, USA

22 3: Department for early prehistory and quaternary ecology, University of

23 Tübingen, 72070 Tübingen, Germany

24

25

26

Abstract 
27 Many animals, and in particular great apes, show evidence of culture, in the

28 sense of having multiple innovations in multiple domains that are

29 influenced by social learning. But only humans show strong evidence of

30 complex, cumulative culture, which is the product of copying and the

31 resulting effect of cumulative cultural evolution. The reasons for this

32 increase in complexity have recently become the subject of extensive

33 debate. Here, we examine these reasons, relying on both comparative and

34 paleoarcheological data. The currently best-supported inference is that

35 culture began to be truly cumulative (and so, outside the primate range)

36 around 500,000 years ago. We suggest that the best explanation for its

37 onset is the emergence of verbal teaching, which requires language and

38 thus probably coevolved with the latter's evolution but also reflects the

39 overall increase in proactive cooperation due to extensive allomaternal

40 care. Imitation, often considered critical, can emerge developmentally in

41 ape-like primates once learned skills are too complex to be easily

42 innovated independently. A subsequent steep increase in cumulative

43 culture, roughly $75 \mathrm{ka}$, may reflect the rise of active novelty seeking

44 (curiosity), which led to a dramatic range expansion and steep increase in

45 the diversity and complexity of material culture. A final, and continuing,

46 period of acceleration began with the Neolithic (agricultural) revolution.

49 Keywords: cumulative culture; stone tools; Out of Africa; imitation; verbal 50 instruction; teaching 
Introduction

Many animals show evidence of social learning, some show traditions, and a subset of these show multiple traditions in a range of domains, ranging from subsistence to comfort behaviors and communication, which also tend to be geographically variable (Whiten et al. 2017). Whiten and van Schaik (2007) proposed to reserve the term

60 culture for the latter level of variation. These cultures generally consist of

61 innovations that, once arisen, increase in frequencies via social learning

62 until stopped by a dispersal barrier, which helps create geographic variation. However, variation may in some cases also be helped by social

64 pressure to be similar to others (e.g. Luncz and Boesch 2014; van de Waal et al. 2017).

Despite the ubiquity of animal cultures, there is very little evidence (apart from the vocal domain, such as some bird and whale songs) for such cultures to be cumulative. A cumulative innovation is one that has a history of repeated copying plus modification of earlier forms, usually by addition (called 'ratcheting' by Tomasello et al. 1993). The paradigmatic case of a

71 cumulative cultural effect is when an individual adds a technique used in a 72 very different context or an entirely novel one to an existing (copied) one, 73 and integrates the two functionally into a new technique. Cumulative

74 culture is therefore culture that may become more complex over time as a

75 result of the cumulation of modifications (we use this neologism to

76 distinguish it from the more general accumulation, which refers to 
increased cultural diversity: Dean et al. 2014). Some primate technology consists of several subparts and has thus been proposed to be cumulative (e.g., Sanz and Morgan 2007). Even so, while it is cumulative in that we see compound innovations, it is as yet unclear whether it meets another frequently used definition of cumulative culture (Boyd and Richerson 1996), i.e. that a naive individual could not independently innovate the more complex variants within its lifetime. In the following we will assume that chimpanzees, and other non-human great apes, do not have cumulative culture in this stronger sense (for a more in-depth review of the matter, see Tennie et al. 2018).

That human culture is cumulative and thus complex for both the material and institutional components is in fact one of the key differences between human and nonhuman cultures. Thus, most of us use technology every day that we could not have invented from scratch and that are the product of long process of cumulating modifications. While the study of cultural evolution in humans has become a thriving enterprise (Mesoudi 2016), explanations for the origin of this complexity remain elusive. The most popular idea is that cumulative culture became possible once humans evolved sophisticated imitation abilities and also teaching (Galef 1992; Tomasello 1999; Tennie et al. 2009; Lewis and Laland 2012), i.e. when they were able to pass on copies. However, when and why this happened during hominin evolution remains unresolved, despite increasing interest by behavioral biologists and psychologists (e.g. Dean et al. 2014; Kempe et al. 2014; van Schaik 2016; Laland 2017; Tennie et al. 2017). 
102 based on copying was not specified. By default, there is a widespread

103 (though rarely made explicit) assumption that the smoking gun of copying

104 can be seen in the origin of any (and thus lithic) technology in the record

105 (Foley and Lahr 2003), although this assumption chose to treat as

106 irrelevant obvious cases of tool use in the animal kingdom not usually seen

107 as a product of cumulative culture (beaver dams, bird nests etc.). And so,

108 cumulative culture was often, and thus tellingly implicitly, assumed to have

109 started with the onset of the Oldowan at 2.6 Ma or perhaps even with what

110 has been called the Lomekwian at $3.3 \mathrm{Ma}$ (Harmand et al. 2015). This early

111 start has rarely been questioned, but counterarguments are on the rise. For

112 example, Tennie et al. $(2016,2017)$, partly drawing on great ape

113 observations, suggested a far more recent origin of cumulative technology

114 (at the earliest in the Acheulean, but probably later). We will accept this

115 assessment here, but also delineate two subsequent periods of accelerated

116 increases in complexity and evaluate hypotheses to explain them.

117 At the current state of knowledge, any conclusions will have to

118 remain tentative. Nonetheless, the value of this approach is that integrating

119 information from living animals encourages us to consider individual,

120 social and demographic variables that are not always taken into account.

\section{The origin and rise of cumulative culture}

124 In this section, we examine the timing of the first clear signs of

125 cumulative cultural evolution during hominin evolution (and thus of 
126 cultural complexity beyond the range of extant great apes) and of

127 subsequent periods of apparent acceleration in the cumulation process.

128 Wild great apes produce innovations via others through social-

129 learning mechanisms that largely amount to socially mediated serial

130 reinnovations (Bandini and Tennie 2017), and so innovations, even if

131 occasionally consisting of several steps, nevertheless remain within the

132 species' zone of latent solutions (Tennie et al. 2009), i.e. the set of

133 innovations that individuals of the species can in principle independently

134 invent during their lifetime. As a result, cultural repertoires of populations

135 may come to differ (in the interplay between environmental and genetic

136 differences, together with socially mediated reinnovations). However,

137 while they may increase in diversity, they tend not to increase in

138 complexity: there is no clear ratcheting (Tomasello 1999; Boyd and

139 Richerson 1996).

140 Tennie et al. $(2016,2017)$ argued that our ancestors (hominins)

141 engaged in the same thing (socially mediated reinnovation) for most of

142 their existence. The record of our early stone-tool making ancestors

143 reveals hundreds of thousands of years of stasis (variance exists, but

144 around a mean) in both the Oldowan and Acheulean industries, which is

145 unlikely if they really had represented cumulative culture (i.e. the passing

146 on of actual copies of variants which automatically would have led to

147 variants outside the relevant species' respective zones of latent solutions).

148 This does not require that the ability to produce these technologies was

149 genetically based in the sense of being developmentally strongly canalized

150 (a view taken by Corbey et al. 2016), but that it was more likely cultural in 
151 the same sense that extant primate technology is, relying on some form of

152 social learning and socially induced individual practice (Schuppli et al.

153 2016). But if the practice part receives no social inputs that provide

154 guidance over and above what the individual will likely converge on, and if

155 no (or not enough, or too rarely) details are copied, i.e. if there is neither

156 teaching nor imitation able to lead to copies, there will be a limit on the

157 level of complexity that is achieved. Though of course, depending on

158 factors such as a species' cognition and anatomy, concrete goals, raw

159 material selectivity, ecological dependence on stone tools, life history (esp.

160 maximum age) and perhaps most importantly, individual practice, the

161 results would always show variability. But they would lack (as they do) a

162 fast direction (the latter the hallmark of cumulative culture; compare

163 Kempe et al. 2012).

164 With the origin of the prepared-core or mode-3 technology (grading

165 into the Middle Stone Age), we see the emergence of even more complex

166 tools, and with it a major leap in efficiency (cf. Muller and Clarkson 2016).

167 We place this origin at ca 500 ka because both later $H$. heidelbergensis

168 (a.k.a. archaic sapiens) and early H. neanderthalensis show many

169 similarities in technology and other aspects of culture, which implies that

170 their common ancestors around that time had similar capabilities. The

171 technological changes included making stone points from prepared cores,

172 and then hafting them onto wooden handles using adhesive peck (which

173 also needs preparation) and special binding materials (Haidle et al. 2015).

174 This complexity and interdependency at least suggests new processes

175 were at work. These tools might therefore have been outside the zone of 
latent solutions of the species concerned, Homo heidelbergensis (Mithen 1996), since it would (at least with current knowledge) seem unlikely that even a modern human could independently rediscover this sequence from scratch. Following this logic, subsequent technologies should have been even more likely cumulative (i.e. as they contained even longer interdependent sequences). While this conclusion is preliminary, so far, no broadly accepted explanation has been offered for the origin of mode-3 technology, which happened when the species had reached a brain size of $1000-1200 \mathrm{~cm}^{3}$, over twice that of the extant great apes. Obviously, this does not mean the cumulation process was smooth. Paleolithic archeologists have long recognized the clear uptick in complexity and diversity during the Upper Paleolithic (McBrearty and Brooks 2000; Klein 2008), which is also widely held responsible for the demographic expansion known as Out-of-Africa, which took off after ca 75 ka and led to a massive population increase, largely through the colonization of all continents but Antarctica (Hoffecker and Hoffecker 2017), as well as increased technological complexity (Klein 2008). To Harcourt (2015) this rapid and sustained colonization of unfamiliar regions implies a sudden, dramatic leap in true curiosity in the form of novelty seeking and extensive exploration. Some have even claimed that this process left a genetic footprint (Matthews and Butler 2011; Gören 2016; but see Campbell and Barone 2012). The last major increase in the rate of technological ratcheting began after the origin of sedentary life and increasingly intensive agriculture at ca. 10 ka (the Neolithic Revolution). Very soon after the Neolithic, 
metallurgy arose, followed by an unprecedented rise in complexity of technology and institutions. It is broadly agreed that this steep increase in

203 the rate of cultural evolution was due to the origin of sedentism and the

204 development of ever more efficient agricultural techniques (Scott 2017),

205 including specialization, accompanied by a veritable population explosion

206 and dramatic changes in social organization (Nolan and Lenski 2009;

207 Diamond 2012). We will therefore not pursue the explanations for this last 208 event, but focus on the first two.

\section{Modeling cumulative culture}

A variety of factors may favor cumulative cultural evolution. How

213 are we to tie its origin and subsequent changes in its pace to the most

214 relevant variables? Culture obviously relies on innovation and subsequent

215 increases in the frequencies of these innovations in the form of socially

216 induced reinnovation or copying. In cumulative culture, the complexity of a

217 particular innovation in a population is a function of the balance of

218 cumulation through additional innovation or immigration and loss of

219 complexity or even extinction through failure of transmission.

Theoretical attempts to understand this cumulation process follow

221 two broad approaches. The first approach focuses on the fidelity of

222 transmission. Lewis and Laland (2012) exemplify this approach. Pradhan

223 et al. (2012) are similar, but explicitly derive their model from the

224 observed natural history of great ape technology, and we will expand on it

225 here. The model incorporates innovation rates $(\varepsilon)$ and transmission rates, 
with the latter a function of the individual's ability to learn socially $(\alpha)$ and

227 the number of tolerant experts and their involvement ( $\kappa)$. In addition, it

228 takes into account population size $(\mathrm{N})$ and life history (mortality rates and

229 the duration of immaturity and thus learning). The goal is to think

230 systematically about how changes in the values of the relevant variables

231 will affect the degree of cumulation, without changes in brain size and thus

232 intrinsic cognitive ability. In the following account, we will use previously

233 unpublished results from this model to illustrate some conclusions (see

234 Pradhan et al. 2012, for full details).

In the Pradhan et al. (2012) model, innovation is favored by larger

236 population sizes and exchange between populations, and by greater

237 individual innovativeness (intelligence, curiosity). Social transmission is

238 favored by longer contact between generations, by population size and by

239 social network structure (tolerance produces a greater number of role

240 models for naïve learners). Social transmission also depends on features of

241 the learners, especially their ability to actually pick up new innovations, i.e.

242 by their ability to actually copy (e.g. to imitate actions and action

243 sequences that are novel to them), and by features of the experts, in

244 particular the degree to which they are actively aiming to pass on their

245 skills (their levels of teaching). Finally, social transmission depends on life

246 history, in the form of mean lifespan, and thus opportunities for social

247 transmission of innovations (each individual is born naïve), and the

248 duration of the immature time window of social learning.

249 The second approach -was introduced by Henrich (2004). The

250 models, dubbed treadmill models, focus on the fate of a particular skill, 
251 which is transmitted to the next generation, whose members show a

252 distribution of skill levels around the role model's skill level. Learners are

253 assumed to focus on the most skilled individuals for learning, but commit

254 errors when learning, such that the mean skill level will decrease.

255 However, there is variance in the error, which is positively linked to

256 population size, and presumably also to overall complexity (see Andersson

257 and Read 2016). Thus, if population size is large enough, the most skilled

258 individuals in the next generation end up being more skilled than their role

259 models, and skill level will increase. Notice that in these models, which

260 concentrate on the most complex skills, there is no teaching or other

261 processes guaranteeing fidelity of transmission. However, there is a direct

262 link between demography and skill level: that latter goes down in small

263 populations, up in large ones. While we focus on the fidelity approach, we

264 will bring in comparisons with the second where relevant.

265

266

267 Explaining the origin and elaboration of human cumulative culture

268 We start with the variables affecting innovation and then turn to

269 those affecting social transmission.

271 Innovation: population size and social networks

272 Population size can affect innovation in an entirely passive way: if

273 each individual has a particular probability of making an innovation $(\varepsilon)$,

274 then in a larger population (defined as a collection of individuals that are in

275 contact), more innovations will arise per unit time ( $\mathrm{N} \times \varepsilon)$. However, in a 
species capable of true social transmission of skill (copying) and where

277 individuals are in contact, once innovations arise in a given population,

278 they can then be passed on and so be retained. This leads to a higher level

279 of cultural complexity (namely when innovations build upon earlier

280 innovations, i.e. the ratchet effect). Fig. 1 illustrates this for the model of

281 Pradhan et al. (2012), where we imposed a maximum level of complexity of

282 three steps of cumulation or ratcheting. Larger population size greatly

283 speeds up the technological cumulation process, not just by favoring the

284 emergence of new innovations but above all by improved retention. Even

285 so, for each set of parameter values, a maximum complexity will eventually

286 be reached, due to time constraints on learning during development. Lewis

287 and Laland (2012) reach the same conclusion in their unbounded model,

288 stressing that fidelity of transmission played a greater role than

289 innovation. However, they also show that the kind of innovation with the

290 strongest effect is trait combination, a source of innovation where two

291 existing techniques are combined into a novel combination. Finally, as we

292 noted above, in treadmill models (Henrich 2004; Powell et al. 2009)

293 cumulative evolution is directly proportional to population size in both

294 directions. Thus, larger populations should have more complex cultures,

295 with no upper limit.

296 Perhaps surprisingly, the ethnographic evidence for a strong effect

297 of demography is mixed (e.g., Collard et al. 2013; Andersson and Read

298 2016; Vaesen et al. 2016), and instead suggests that resource pressure or

299 environmental risk may better predict innovation repertoires among

300 foragers. One possible reason is that in a given habitat, with a particular 
constellation of ecological challenges, even a smaller population may eventually reach the equilibrium technology level if there is enough time and no catastrophes, especially when nomadism imposes strict limits on material culture. A recent study (Fogarty and Creanza 2017) strongly supports this interpretation, both empirically and theoretically. This implies that demography need not have been a causal factor

307 while all humans were still fully nomadic foragers, i.e. until well into the Upper Paleolithic. Indeed, both archeology (Klein and Steele 2013) and genetics (Li and Durbin 2011) suggest effective population sizes were quite

310 modest around 75 ka when humans had already developed effective new

311 technology and began to move far out of Africa (Klein 2008). Thus, there is

312 little empirical evidence for the proposition that population size can affect

313 cultural evolution directly when lucky innovations start a positive

314 feedback loop between innovation and population (cf. Laland 2017),

315 although all approaches predict it.

316 A more indirect effect of demography may therefore have been

317 more instrumental. Long-distance contact between groups can create a

318 much larger social network and thus allow for rare innovations to spread

319 far and wide (Henrich 2004; Powell et al. 2009). Both the number and the 320 size of subpopulations as well as the rate of migration between them affect 321 the cumulation process (Powell et al. 2009). We can use the Pradhan et al. 322 (2012) model to illustrate the powerful effect of cultural diffusion. We can 323 once a year randomly pick a single individual in a population of 500 and

324 increase its technology level by one year. Fig. 2 shows how this can 325 massively enhance a population's technological complexity. Thus, cultural 
diffusion through contact can easily swamp any effects of local population

327 size, in both directions. Such contact with other groups has been shown to

328 be important among extant nomadic foragers, whose visits to other

329 communities allowed them to observe hundreds of experts over a lifetime

330 (Hill et al. 2014). But archeologically, the first unambiguous evidence of

331 long-distance trade and thus such non-hostile contacts between societies is

332 at $200 \mathrm{ka}$ (Blegen 2017), well after the time suggested here as the

333 appearance of the first truly cumulative technology. However, the origin of

334 full-fledged language (Dediu and Levinson 2013) at around 500 ka may

335 have facilitated non-hostile contact between neighboring communities and

336 so facilitated cultural diffusion. Thus, indirect demographic (social

337 network) effects may well have been stronger than actual community sizes

338 or population densities.

340 Innovation: curiosity

341 In addition to external factors such as population size and contact,

342 intrinsic factors may also affect innovation rate. Across species, various

343 studies have found a correlation between relative brain size and the

344 frequency of observed innovations (Reader and Laland 2002). However,

345 this correlation need not reflect a directly causal effect of brain size on

346 innovation tendency, because there may be a major effect of the retention

347 of innovations helped by social learning (van Schaik et al. 2016), which is

348 also far more likely in more encephalized species (Reader and Laland

349 2002). Moreover, the best evidence concerns survival upon release into 
novel regions, and thus need not reflect innovativeness under normal conditions (e.g. Sol et al. 2008).

We raise this more complex interpretation because wild apes show a striking lack of curiosity (novelty seeking plus extensive exploration). Thus, young orangutans are selectively curious, exploring items novel to them only after trusted older experts, initially always their mothers, have handled them (Schuppli et al. 2016). Such targeted exploration is both effective and safe. All wild orangutans strongly avoid any novel items placed in their environments (Forss et al. 2015), as do many other species (Forss et al. 2017). Gruber et al. (2009) showed experimentally that exploration of problem-solving opportunities is also minimal: adult chimpanzees in the wild do not recognize obvious alternative solutions to a problem (obtaining honey from a tree hole), even when the solution is observed, and even if the solution is within reach of individuals that have not had the individual experience to develop functional fixedness (cf. Hanus et al. 2011). Overall, then, the most encephalized species in the wild stand out more by their conservatism than their innovativeness. We therefore suspect that increased brain size need not directly translate into clearly higher innovation rates in hominoids, and thus hominins. Accordingly, despite decades of intensive field study of great apes, there is indeed remarkably little evidence for the origin of novel innovations, let alone for such that subsequently increase in frequency (e.g. Yamamoto et al. 2008). The natural examples that are well documented are minor variants on existing themes, such as moss sponging rather than the already present leaf sponging (Hobaiter et al. 2014), which may not even 
375 be cognitively distinct to the users. Stone tool use, the only known modern

376 primate technology that left directly recognizable debris in the

377 archaeological record (plant material does not last long in these

378 conditions), has been shown to be old. For instance, Mercader et al. (2007)

379 showed that nut cracking by chimpanzees using stone tools is at least

3804,300 years old, and potentially much older, and has fundamentally

381 remained the same since that time (Dean et al. 2014).

Wild apes thus show a remarkable conservatism and lack of

383 curiosity (e.g. van Schaik et al. 2016). This tendency is almost certainly

384 adaptive in that novel items are potentially dangerous and social

385 information, when available, is therefore preferred, especially in species

386 with a long life expectancy (Forss et al. 2017). The same conclusion might

387 well apply to our hominin ancestors during much of human evolution.

388 Many people may find this conclusion surprising, because when they think

389 of apes they have in mind captive apes, which are indeed rightly renowned

390 for their innovativeness. In fact, Damerius et al. (2017a, b; see also Forss et

391 al. 2015) showed that captive orangutans are far more curious than their

392 wild counterparts, at least in part because captive orangutans have had

393 extensive contact with humans from a very early age, which unleashed

394 their curiosity. The erosion of the reluctance to explore novelty in captivity

395 (especially when enculturated) indicates that novelty seeking is a latent

396 ability that can be elicited by particular developmental conditions.

Because modern humans are often curious, the challenge is to

398 identify when our ancestors became more like captive apes. In the wild the

399 dormant potential is most likely expressed under conditions of great 
necessity, when regular subsistence techniques have suddenly become

401 ineffective. This would explain the increase in realized technology shown

402 under environmental risk (Andersson and Read 2016; Fogarty and Creanza

403 2017), when necessity clearly acts as the mother of invention.

\section{Social transmission: imitation}

One current view holds that great apes largely lack cumulative

culture because their copying abilities are not good enough: while they can individually innovate behavior (including tool making and tool use), they seem to lack the motivation and/or ability to copy the styles and forms of

410 others' innovations (Tennie et al. 2018). It is indeed clear that a modest

411 increase in the efficiency of social transmission due to improved social

412 learning (or help in the form of teaching; see below) can produce a steep

413 increase in technology level (Lewis and Laland 2012). Fig. 3, based on the

414 Pradhan et al. (2012) model, illustrates this. Indeed, given that the baseline 415 value for wild great apes learning tool use, $\alpha$, is 0.25 at best, it is clear how

416 even a small increase in the efficiency of social transmission can provide a 417 major boost to technological cumulation.

418 Indeed, it is often argued that cumulative culture requires faithful

419 transmission so as to create a uniform platform that stays intact for long

420 enough for subsequent modifications to happen "on top" (Tennie et al.

421 2009; Lewis and Laland 2012; Heyes 2018). The key improvement would

422 involve a move away from using social learning mechanisms that are

423 merely socially elicited individual learning (non-copying social learning;

424 widespread in the animal kingdom) toward copying social learning (which 
425 is then able to transmit form, i.e. hierarchical and/or style components of

426 demonstrations - a crucial pre-requisite of the ratchet effect; Tennie et al.

427 2018). Once copying of actions (imitation) is in place, and especially the

428 copying of novel actions (broader range), it can be applied in a broad range

429 of conditions (e.g. communication [itself able to increase fidelity] and tool

430 making and use), and raises transmission fidelity. And while a detailed

431 physical understanding can theoretically allow observers to re-engineer

432 technology (various forms of so-called emulation learning), even here

433 action copying can be of benefit, because actions are hierarchically higher

434 than environmental results (they cause these results and thus come first)

435 and also bear an intimate correlation with their results (action A on object

$436 \mathrm{X}$ may reliably produce result A), and so the simultaneous copying of both

437 actions and results disproportionately increases fidelity (Acerbi and

438 Tennie 2016). For these combined reasons, action copying favors cultural

439 evolution.

440 Do great apes copy actions in this way? Evidence for action copying

441 in wild great apes (and, likewise, unenculturated captive apes) is debated,

442 but weak at best (CT et al. unpublished data), whereas enculturated great

443 apes, i.e. individuals that grew up with humans and were treated much like

444 human babies are, do show evidence of action copying (Russon and

445 Galdikas 1993; Tomasello et al. 1993; Subiaul 2016), along with the

446 requisite changes in brain structure that are required and that resulted

447 from such "training" (Bard and Hopkins 2018; Pope et al. 2018). This

448 indicates that apes can be induced to socially construct the ability to

449 imitate by exposure to rich inputs, perhaps especially numerous novel 
450 actions and/or long sequences of actions with unexpected outcomes.

451 Indeed, Catmur and Heyes (2018) argue that imitation in humans is

452 similarly constructed during development based on social inputs (i.e. is a

453 “cognitive gadget”, Heyes 2018)

454 The upshot of this recent increase in our understanding of ape

455 imitation is that imitation is possibly no longer the magic bullet for the

456 evolution of cumulative culture. Clearly, the ability to engage in imitation,

457 including production imitation (sensu Byrne 2002), lies - as a potential -

458 dormant in every great ape, and can be constructed when the inputs are

459 right or perhaps even if they require it (we postpone asking about the

460 origin of these complex inputs to the discussion).

461

462

Social transmission: teaching

In species capable of social learning of copying types, teaching -

464 social learning with an actively involved demonstrator - provides a major

465 boost in transmission efficiency (Fogarty et al. 2011; Dean et al. 2014;

466 Morgan et al. 2015) and perhaps also in the possible complexity of

467 innovations that can be copied. Teaching in this way is seen in large-scale

468 human societies (Csibra and Gergely 2011) and, albeit less pervasively,

469 also in hunter-gatherers (Kline 2014; Hewlett and Roulette 2016), whereas

470 despite all efforts to detect it, the evidence for great apes is extremely thin

471 (Hoppitt and Laland 2013; Moore and Tennie 2015). However, (non-

472 intentional) teaching is common among primates that are cooperative

473 breeders (Humle and Snowdon 2008; Rapaport 2011). Because teaching

474 can provide a boost to transmission fidelity, and can initially do so without 
requiring the evolution of complex cognitive machinery, it is among the most important drivers of cultural complexity (Tomasello 2009; Pradhan et al. 2012; Dean et al. 2014). Thus, the timing of the origin of teaching may hint at the origin of cumulative technology (Fogarty et al. 2011; Laland 2017). Note however, that teaching should always be split up by the underlying social learning mechanisms (Hoppitt et al. 2008). Here, we are interested in teaching forms that use social learning mechanisms involving copying (which is why we do not elaborate on the occurrences of other, non-copying forms of teaching in the animal kingdom; see, e.g. Hoppitt et al. 2008).

\section{Discussion}

When trying to identify the variables leading to cumulative technology, it is generally most profitable to look for changes in the external variables, either the habitat (as driven by the rate and amplitude of climate change: Richerson and Boyd 2000) or other, habitat-driven aspects of the social system, such as the rearing system (van Schaik and Burkart 2010) and environmental risk (Andersson and Read 2016). Above, we suggested that the archeological record does not support increased population size or a positive feedback loop between population size and innovation as the sole cause for the onset of cumulative technology. Of course, it remains possible that a relatively short period of favorable climate pushed up (some) hominin populations, and so gave rise to innovations that raised carrying capacity enough to unleash a positive 
500 feedback loop between population size and innovation repertoires.

501 However, the lack of clear evidence for a sustained increase in population

502 size during the Middle Pleistocene does not support this possibility.

503 Instead, we identified the onset of language-buttressed teaching involving

504 copying of novel actions and, later, curiosity as key variables for the onset

505 of cumulative culture and its acceleration before Out-of-Africa, respectively

506 (Table 1).

507

The dawn of cumulative cultural evolution

Roughly following Tennie et al. (2016), we tentatively pinpointed

510 the period after around 500 ka to mark the onset of the first cumulative

511 technology. This suggests that Homo heidelbergensis evolved a new

512 lifestyle. Indeed, around this time or somewhat later (the latter perhaps

513 due to the incomplete record in most of Africa) the first solid evidence is

514 found for systematic controlled use of fire (Roebroeks and Villa 2011), and

515 especially for new technology, including composite tools (Wilkins et al.

516 2012), the use of throwing spears (Thieme 1997), and the inferred use of

517 full-fledged language (Dediu and Levinson 2013). This latter factor may

518 hold the key.

519 The classic candidate processes to explain the origin of cumulative

520 culture are high-fidelity copying (especially imitation) and teaching

521 (Tennie et al. 2009; Laland 2017). We tentatively discounted the limiting

522 role of imitation since great apes can be led to developmentally construct

523 the ability (as a "cognitive gadget” sensu Heyes 2018) in conditions where

524 more complex actions or action sequences must be learned. This leaves 
525 teaching (cf. Tomasello 2009; Fogarty et al. 2011). Because teaching

526 improves transmission and so retention of innovations, it favors increased

527 innovation capacity whenever innovations enhance fitness. Modern

528 humans, in addition to silently providing examples and physically shaping

529 others' behavior (an understudied form of true social transmission), often

530 rely on language in instruction. Indeed, experiments have shown that

531 learning to make stone tools becomes far more efficient when verbal

532 instruction is added to the mix (Morgan et al. 2015; cf. Zwirner and

533 Thornton 2015). This suggests that effective teaching, especially of

534 functionally opaque actions that are part of a longer chain and which

535 require copying for their acquisition, could only become prominent after

536 language had evolved to a sufficient level of complexity to make this

537 possible. Once it was in place, correlated evolution between teaching,

538 imitation and cumulative culture could ensue (Laland 2017).

539 Language did not evolve overnight, and precursors must have

540 existed (Tomasello et al. 2012). Teaching is more common among

541 cooperative breeders (Rapaport 2011), and hominins may have become

542 cooperative breeders and thus more cooperative than extant great apes

543 (Tennie et al. 2016) well before they invented the prepared core technique

544 (Hrdy 2009; Isler and van Schaik 2012). The fundamentally prosocial

545 attitudes toward fellow group members that characterize cooperative

546 breeding (Burkart et al. 2014) will have favored the evolution of both

547 teaching and language (Burkart et al. 2018), as teaching is, in essence,

548 prosocial: Tennie et al. 2009; van Schaik and Burkart 2010). Thus the

549 combination of teaching and language produced cumulative culture. The 

plausibility of this model is enhanced by the fact that the external factor

551 producing the onset of cumulative culture was not a cognitive one but

552 rather a change in the rearing and social system (van Schaik and Burkart 553 2010; Laland 2017). Assuming an externally caused increase in cognition

554 merely moves the question to the source of this increase. However,

555 cooperative breeding (and, with it, teaching) may plausibly have been

556 elicited by increasing climate fluctuations (cf. Richerson and Boyd 2000),

557 because it is known to be favored when productivity declines (Griesser et 558 al. 2017) and among mammals, is overrepresented in the most 559 inhospitable climates (Lukas and Clutton-Brock 2017).

560 This leaves the question how the adoption of language-buttressed 561 teaching may have led to greater innovativeness in our ancestors. Once 562 effective teaching exists, selection will favor individuals who acquire the 563 local population's set of innovations as fully and rapidly as possible.

564 However, this selection also automatically improves individual or asocial 565 learning skills (van Schaik and Burkart 2011; Heyes 2012), leading to 566 better and faster innovation, which in turn favors the developmental 567 construction of imitation (see above). These mutual positive influences 568 create a positive feedback loop, leading to coevolving innovation and 569 imitation abilities. This loop also includes changes in life history (e.g. by 570 slowing down development and expanding the learning period to beyond 571 sexual maturity) and brain size. This process may bring about a quantum 572 leap in the complexity of technology because teaching (because of its

573 highly increased fidelity) allows naïve individuals to bypass the historical 574 sequence of innovation steps that led to the current, complex technique 
and simply skip to the current technique. Such shortcutting also increases

576 the likelihood that young individuals make additional innovations (often

577 by mistake; cf. Henrich 2004; Eerkens and Lipo 2005) that improve upon

578 the existing technique.

Overall, then, the process that produced both effective language and

580 teaching in a coevolutionary process is the most plausible candidate for the

581 origin of complex and truly cumulative material culture in hominin

582 evolution.

583

The origin of curiosity

The idea that a gradual increase in cumulative culture in Africa was the root cause of the rich and complex material culture of the humans that appeared in Europe at ca 42 ka (McBrearty and Brooks 2000) suggests no step-wise change in the cumulation process. Nonetheless, many suggest that some major new factor underlies by the rapid, sustained Out-of-Africa dispersal that began around $75 \mathrm{ka}$, and by the continuing rapid increase in complexity since then. As discussed above, a sudden increase in novelty seeking or curiosity was recently suggested as the key underlying change. We noted that in great apes, curiosity can be elicited even when it

594 normally lies dormant. This idea lends greater plausibility to the novelty-

595 seeking hypothesis, because the existence of a phenotypic switch to turn

596 on curiosity enables rapid responses during a brief period in which regular

597 techniques have become ineffective. If the onset of curiosity had required

598 genetic responses, local populations would probably have gone extinct well

599 before they could respond adaptively. It is also possible, as suggested by 
600 the geographic gradient in variants of the dopamine receptor gene

601 (Matthews et al. 2011; Gören 2016), that selection on the suppression of

602 previously maladaptive curiosity was relaxed, allowing the variant alleles

603 of the dopamine receptor gene to spread during to the dramatic range

604 expansion.

605 Obviously, future work is needed to evaluate this radical idea, in

606 particular with respect to the event that elicited this shift in some local

607 population(s). For example, the Toba eruption may not have led to a

608 population collapse in Africa and adjacent regions, as previously claimed

609 (Ambrose 2003), but it may have produced a brief ecological crisis, serious

610 enough to lead some individuals to lose their neophobia and try out

611 unusual resources or habitats.

The Neolithic revolution

The origin of agriculture was preceded by a period in which

615 foragers in some regions became more sedentary. Sedentary foragers have

616 more, and more complex, technology than nomadic ones (Torrence 2001).

617 Agriculture added another major impetus to expand technology, partly

618 made possible by specialization, but also led to a strong increase in

619 population size and contact between societies through trade or conquest

620 (Scott 2017). Large populations produce more innovations passively (by

621 greater numbers or greater diffusion), by allowing specialization, or by

622 producing wars and ecological crises that necessitated innovations

623 (Fogarty and Creanza 2017). In this phase, clearly the feedback loop

624 between population size, social exchange and the accompanying cultural 
625 diffusion had become major engines of cumulative culture, with seemingly

626 open-ended outcome (Laland 2017).

627

628

\section{Acknowledgments}

630 We thank Peter Kappeler for the invitation, and Kevin Laland and an

631 anonymous reviewer for valuable comments. CPvS thanks the Swiss

632 National Science Foundation (grant 310030B_160363/1). This work has

633 received funding from the European Research Council (ERC) under the

634 European Union's Horizon 2020 research and innovation programme

635 (grant agreement $\mathrm{n}^{\circ}$ 714658; STONECULT project).

636

637

638 Conflict of Interest

639 The authors declare that they have no conflict of interest. 


\section{References}

641 Acerbi A, Tennie C (2016) The role of redundant information in cultural transmission and cultural stabilization. J Comp Psychol 130:62-70

Ambrose SH (2003) Did the super-eruption of Toba cause a human population bottleneck? Reply to Gathorne-Hardy and Harcourt-Smith. J Hum Evol $45: 231-237$

646 Andersson C, Read D (2016) The evolution of cultural complexity: not by the treadmill alone. Curr Anthropol 57:261-286

Bandini E, Tennie C (2017) Spontaneous reoccurrence of "scooping", a wild tool-use behaviour, in naïve chimpanzees. PeerJ 5:e3814.

Bard KA, Hopkins WD (2018) Early socioemotional intervention mediates longterm effects of atypical rearing on structural covariation in gray matter in adult chimpanzees. Psychol Sci 29:594-603

Blegen N (2017) The earliest long-distance obsidian transport: evidence from the $\approx 200$ ka Middle Stone Age Sibilo School Road Site, Baringo, Kenya. J Hum Evol 103:1-19

Boyd R, Richerson PJ (1996) Why culture is common, but cultural evolution is rare. P Brit Acad 88:77-93

Burkart JM, Allon O, Amici F et al (2014) The evolutionary origin of human hyper-cooperation. Nat Commun 5:4747

Burkart JM, Martins EG, Miss F, Zürcher Y (2018) From sharing food to sharing information: cooperative breeding and language evolution. Interact Stud

663 Byrne RW (2002) Imitation of novel complex action: what does the evidence from animals mean? Adv Stud Behav 31:77-105 
668 Catmur C, Heyes C (2017) Mirroring "meaningful" actions: sensorimotor learning modulates imitation of goal-directed actions. Q J Exp Psychol 19:1-13

671 Collard M, Buchanan B, O'Brien MJ, Scholnick J (2013) Risk, mobility or population size? Drivers of technological richness among contact-period

Corbey R, Jagich A, Vaesen K, Collard M (2016) The Acheulean handaxe: more like a bird's song than a Beatles' tune? Evol Anthropol 25:6-19

Csibra G, Gergely G (2011) Natural pedagogy as evolutionary adaptation. Phil Trans R Soc B 366:1149-1157

Damerius LA, Forss SIF, Kosonen ZK et al (2017a) Orientation towards humans predicts cognitive performance in orang-utans. Sci Rep 7:40052

Damerius L, Graber SM, Willems EP, van Schaik CP (2017b) Curiosity boosts orang-utan problem-solving ability. Anim Behav 134:57-70

Dean LG, Vale GL, Laland KN, Flynn E, Kendal RL (2014) Human cumulative culture: a comparative perspective. Biol Rev 89:284-301

Dediu D, Levinson SC (2013) On the antiquity of language: the reinterpretation of Neandertal linguistic capacities and its consequences. Front Psychol $4: 397$

Diamond J (2012) The world until yesterday: What we can learn from 689 traditional societies. Viking, New York generation of variation in material culture and the archaeological record. J Anthropol Archaeol 24:316-334 
Fogarty L, Creanza N (2017). The niche construction of cultural complexity: interactions between innovations, population size and the environment. Phil Trans R Soc B 372:20160428

Fogarty L, Strimling P, Laland KN (2011) The evolution of teaching. Evolution $65: 2760-2770$

Foley R, Lahr MM (2003) On stony ground: lithic technology, human evolution, and the emergence of culture. Evol Anthropol 12:109-22

Forss SIF, Koski SE, van Schaik CP (2017) Explaining the paradox of neophobic explorers: The social information hypothesis. Int J Primatol 38:799-822

Forss SIF, Schuppli C, Haiden D, Zweifel N, van Schaik CP (2015) Contrasting responses to novelty by wild and captive orangutans. Am J Primatol $77: 1109-1121$

Galef BG Jr (1992) The question of animal culture. Hum Nat 3:157-178

Gören E (2016) The biogeographic origins of novelty-seeking traits. Evol Hum Behav 37:456-469

Griesser M, Drobniak SM, Nakagawa S, Botero CA (2017) Family living sets the stage for cooperative breeding and ecological resilience in birds. PLOS Biol 15:e2000483

Gruber T, Muller MN, Strimling P, Wrangham RW, Zuberbühler K (2009) Wild chimpanzees rely on cultural knowledge to solve an experimental honey acquisition task. Curr Biol 19:1806-1810

Haidle MN, Bolus M, Collard M et al (2015) The nature of culture: an eight-grade model for the evolution and expansion of cultural capacities in hominins and other animals. J Anthropol Sci 93:43-70

Hanus D, Mendes N, Tennie C, Call J (2011) Comparing the performances of apes (Gorilla gorilla, Pan troglodytes, Pongo pygmaeus) and human children (Homo sapiens) in the floating peanut task. PLoS ONE 6:e19555 
Harcourt A (2015) Humankind: How biology and geography shape human diversity. Pegasus Books, New York

Harmand S, Lewis JE, Feibel CS et al (2015) 3.3-million-year-old stone tools from Lomekwi 3, West Turkana, Kenya. Nature 521:310-315

Henrich J (2004) Demography and cultural evolution: how adaptive cultural processes can produce maladaptive losses - The Tasmanian case. Am Antiquity 69:197-214

Hewlett BS, Roulette CS (2016) Teaching in hunter-gatherer infancy. R Soc open sci 3:150403

Heyes C (2012) What's social about social learning? J Comp Psych 126:193-202

Heyes C (2018) Cognitive gadgets: the cultural evolution of thinking. Harvard University Press, Cambridge, MA

Hill KR, Wood BM, Baggio J, Hurtado AM, Boyd RT (2014) Hunter-gatherer inter-band interaction rates: implications for cumulative culture. PLoS ONE 9:e102806

Hobaiter C, Poisot T, Zuberbühler K, Hoppitt W, Gruber T (2014) Social network analysis shows direct evidence for social transmission of tool use in wild chimpanzees. PLoS Biol 12:e1001960

Hoffecker JF, Hoffecker IT (2017) Technological complexity and the global dispersal of modern humans. Evol Anthropol 26:285-299

Hoppitt WJ, Brown GR, Kendal R, Rendell L, Thornton A, Webster MM, Laland KN (2008) Lessons from animal teaching. Trends Ecol Evol 23:486-493

Hoppitt WJE, Laland KN (2013) Social Learning: An Introduction to Mechanisms, Methods, and Models. Princeton University Press, Princeton, NJ

Hrdy SB (2009) Mothers and Others: The Evolutionary Origins of Mutual Understanding. Harvard University Press, Cambridge 
Humle T, Snowdon CT (2008) Socially biased learning in the acquisition of a complex foraging task in juvenile cottontop tamarins, Saguinus oedipus. Anim Behav 75:267-277

Isler K, van Schaik CP (2012) How our ancestors broke through the gray ceiling: comparative evidence for cooperative breeding in early Homo. Curr Anthropol 53:S453-S465

Kempe M, Lycett S, Mesoudi A (2012) An experimental test of the accumulated copying error model of cultural mutation for Acheulean handaxe size. PLoS ONE 7:e48333.

Kempe M, Lycett SJ, Mesoudi A (2014) From cultural traditions to cumulative culture: parameterizing the differences between human and nonhuman culture. J Theor Biol 359:29-36

Klein RG (2008) Out of Africa and the revolution of human behavior. Evol Anthropol 17:267-281

Klein RG, Steele TE (2013) Archaeological shellfish size and later human evolution in Africa. P Natl Acad Sci USA 110:10910-10915

Kline MA (2015) How to learn about teaching: An evolutionary framework for the study of teaching behavior in humans and other animals. Behav Brain Sci 38:e31

Laland KN (2017) Darwin's unfinished symphony: how culture made the human mind. Princeton University Press, Princeton, NJ

Lewis HM, Laland KN (2012) Transmission fidelity is the key to the build-up of cumulative culture. Phil Trans R Soc B 367:2171-2180

Li H, Durbin R (2011) Inference of human population history from individual whole-genome sequences. Nature 475:493-496

Lukas D, Clutton-Brock TH (2017) Climate and the distribution of cooperative breeding in mammals R Soc open sci 4:160897 
Luncz LV, Boesch C (2014) Tradition over trend: neighboring chimpanzee communities maintain differences in cultural behavior despite frequent immigration of adult females. Am J Primatol 76:649-657

Matthews LJ, Butler PM (2011) Novelty-seeking DRD4 polymorphisms are associated with human migration distance Out-of-Africa after controlling for neutral population gene structure. Am J Phys Anthropol $145: 382-389$

McBrearty S, Brooks AS (2000) The revolution that wasn't: a new interpretation of the origin of modern human behavior. J Hum Evol 39:453-563

Mercader J, Barton H, Gillespie J, Harris J, Kuhn S, Tyler R, Boesch C (2007) 4,300-year-old chimpanzee sites and the origins of percussive stone technology. P Natl Acad Sci USA 104:3043-3048

Mesoudi A (2016) Cultural evolution: A review of theory, findings and controversies. Evol Theor 43:481-497

Mithen S (1996) The Prehistory of the Mind: The cognitive origins of art, religion and science. Thames and Hudson, London

Morgan TJH, Uomini NT, Rendell LE et al (2015) Experimental evidence for the co-evolution of hominin tool-making teaching and language. Nat Commun 6:6029

Muller A, Clarkson C (2016) Identifying major transitions in the evolution of lithic cutting edge production rates. PLoS ONE 11:e0167244

Nolan P, Lenski G (2009) Human Societies: An introduction to macrosociology, $11^{\text {th }}$ edn. Paradigm Publishers, Boulder, CO

Pope SM, Taglialatela JP, Skiba SA, Hopkins WD (2018) Changes in frontoparietotemporal connectivity following do-as-I-do imitation training in chimpanzees (Pan troglodytes). J Cogn Neurosci 30:421-431

Powell A, Shennan S, Thomas MG (2009) Late Pleistocene demography and the 
802 Pradhan GR, Tennie C, van Schaik CP (2012) Social organization and the evolution of cumulative technology in apes and hominins. J Hum Evol $63: 180-190$

Rapaport LG (2011) Progressive parenting behavior in wild golden lion tamarins. Behav Ecol 22:745-754

Reader SM, Laland KN (2002) Social intelligence, innovation and enhanced brain size in primates. P Natl Acad Sci USA 99:4436-4441

Richerson PJ, Boyd RT (2000) Climate, culture, and the evolution of cognition. In: Heyes C, Huber L (eds) Evolution of Cognition. MIT Press, Cambridge, MA, pp 329-346

Roebroeks W, Villa P (2011) On the earliest evidence for habitual use of fire in Europe. P Natl Acad Sci USA 108:5209-5214

Russon A, Galdikas B (1993) Imitation in ex-captive orangutans. J Comp Psych 107:147-161

816 Sanz CM, Morgan DB (2007) Chimpanzee tool technology in the Goualougo Triangle, Republic of Congo. J Hum Evol 52:420-433 Schaik CP (2016) Observational social learning and socially induced practice of routine skills in immature wild orang-utans. Anim Behav $119: 87-98$

Scott JP (2017) Against the Grain: A deep history of the earliest states. Yale University Press, New Haven

824 Sol D, Bacher S, Reader SM, Lefebvre L (2008) Brain size predicts the success of mammal species introduced into novel environments. Am Nat 172:S63-

827 Subiaul F (2016) What is special about human imitation? A comparison with 
enculturated apes. Behav Sci 6:13

829 Tennie C, Braun DR, Premo LS, McPherron SP (2016) The island test for cumulative culture in the Paleolithic. In: Haidle MN, Conard NJ, Bolus M (eds) The Nature of Culture: Based on an Interdisciplinary Symposium 'The Nature of Culture', Tübingen, Germany. Springer Science+Business

834 Tennie C, Call J, Tomasello M (2009) Ratcheting up the ratchet: on the evolution of cumulative culture. Phil Trans R Soc B 364:2405-2415

Tennie C, Hopper L, van Schaik CP (2018) On the origin of cumulative culture: consideration of the role of copying in culture-dependent traits and a reappraisal of the zone of latent solutions hypothesis In: Ross S, Hopper L (eds) Chimpanzees in Context: A Comparative Perspective on Chimpanzee Behavior, Cognition, Conservation, and Welfare. Chicago University Press, Chicago, IL.

Tennie C, Jensen K, Call J (2016) The nature of prosociality in chimpanzees. Nat

844 Tennie C, Premo LS, Braun DR, McPherron SP (2017) Early stone tools and cultural transmission: Resetting the null hypothesis. Curr Anthropol

847 Thieme H (1997) Lower Palaeolithic hunting spears from Germany. Nature $385: 807-810$

849 Tomasello M (1999) The Cultural Origins of Human Cognition. Harvard University Press, Cambridge, MA

851 Tomasello M (2009) The question of chimpanzee culture, plus postscript (chimpanzee culture 2009). In: Laland KN, Galef BG (eds) The Question of Animal Culture. Harvard University Press, Cambridge, MA, pp 198- 
Tomasello M, Kruger A, Ratner H (1993) Cultural learning. Behav Brain Sci $16: 495-511$

Tomasello M, Melis AP, Tennie C, Wyman E, Herrmann E (2012) Two key steps in the evolution of human cooperation: The interdependence hypothesis. Curr Anthropol 53:673-692 doi:10.1086/668207

Torrence R (2001) Hunter-gatherer technology: macro- and microscale approaches. In: Panter-Brick C, Layton RH, Rowley-Conwy P (eds) Hunter-Gatherers: An Interdisciplinary Perspective. Cambridge University Press, Cambridge, pp 73-98

Vaesen K, Collard M, Cosgrove R, Roebroeks W (2016) Population size does not explain past changes in cultural complexity. P Natl Acad Sci USA 113:E2241-E2247

van de Waal E, van Schaik CP, Whiten A (2017) Resilience of experimentally seeded dietary traditions in wild vervets: Evidence from group fissions. Am J Primatol 79:e22687

van Schaik CP (2016) The primate origins of human nature. John Wiley \& Sons, Hoboken, NJ

van Schaik CP, Burkart JM (2010) Mind the gap: Cooperative breeding and the evolution of our unique features. In: Kappeler PM, Silk J (eds) Mind the Gap: Tracing the origins of Human Universals. Springer, Berlin, pp 477496

van Schaik CP, Burkart JM (2011) Social learning and evolution: the cultural intelligence hypothesis. Phil Trans R Soc B 366:1008-1016 van Schaik CP, Burkart JM, Damerius L, Forss SIF, Koops K, van Noordwijk MA, Schuppli C (2016) The reluctant innovator: orangutans and the phylogeny of creativity. Phil Trans R Soc B 371:20150183

881 Whiten A, Ayala FJ, Feldman MW, Laland KN (2017) The extension of biology 

through culture. P Natl Acad Sci USA 114:7775-7781

883 Whiten A, van Schaik CP (2007) The evolution of animal 'cultures' and social intelligence. Phil Trans R Soc B 362:603-620

885 Wilkins J, Schoville BJ, Brown KS, Chazan M (2012) Evidence for early hafted 886 hunting technology. Science 338:942-946

887 Yamamoto S, Yamakoshi G, Humle T, Matsuzawa T (2008) Invention and 888 modification of a new tool use behavior: Ant-fishing in trees by a wild chimpanzee (Pan troglodytes verus) at Bossou, Guinea. Am J Primatol 70:699-702

891 Zwirner E, Thornton A (2015) Cognitive requirements of cumulative culture: 892 teaching is useful but not essential. Sci Rep 5:16781

893

894 


\section{Figure Captions}

896 Fig. 1

897 Effect of population size (N) on time taken to reach complex technology

898 (here constrained to maximum level 3) when starting from scratch.

899 Detailed methods provided in Pradhan et al. (2012)

900

901 Fig. 2

902 Effect of diffusion on ratcheting. Diffusion was simulated by increasing a

903 single randomly picked individual's technology level by 1 in any given year,

904 in a population of 500 individuals, constraining the maximum technology

905 level at 6 (where $\kappa=2, \alpha=0.4$; for details see Pradhan et al. 2012)

906

$907 \quad$ Fig. 3

908 The time needed to reach a complex level of cumulative technology, as a

909 function of the efficiency of social transmission, for realistic values of great

910 ape sociability $(\kappa=2)$ (for details see Pradhan et al. 2012)

911

912

913 
Click here to access/download Marked manuscript BEAS-D-18-00122_R1_corr with track change.docx 